\title{
EN TORNO A LA PRIMERA TRADUCCIÓN ITALIANA DE EL CRITICÓNDE BALTASAR GRACIÁN
}

En las últimas décadas del siglo xvir salió a la luz la traducción italiana completa de El Criticón ${ }^{1}$, obra en la que Baltasar Gracián había concentrado mayores energías en su último período de actividad. El tipógrafo Nicolò Pezzana publicó la versión italiana en la primavera de $1685^{2}$. Más tarde, el nombre de este impresor se encontrará de nuevo asociado al del jesuita aragonés, figurando al pie de la traducción de El Comulgatorio, obra que Pezzana imprimirá con el título de Meditazioni sopra la Santissima Communione (Venecia, 1714 y 1750), atribuyéndola, en tal ocasión, no ya a Lorenzo sino a Baltasar Gracián³

\section{Características generales}

Desde un mero punto de vista tipográfico nada singular caracteriza esta primera edición italiana de $\mathrm{Il} \mathrm{Criticon}^{4}$. En 1685 se presenta austeramente como un volumen de $24.5 \times 17 \mathrm{cms}$., en cuadernillos de papel de mediana calidad, impreso con tipos menudos y con el texto de la versión dispuesto en doble columna. En el futuro, sobre todo en las reimpresiones diecioches-

${ }^{1}$ Utilizo la ed. de Carlos Vaíllo con pról. de J. M. Blecua, Círculo de Lectores, Barcelona, [1651-1657] 2000. En adelante, EC.

${ }^{2}$ El privilegio de impresión fue concedido el 7 de marzo de 1685 por los "Reformatori dello Studio di Padova". Sólo la traducción inglesa de 1681 precede, en unos pocos años, a la italiana. Las restantes versiones (al francés y alemán) son sucesivas.

${ }^{3}$ La misma traducción, llevada a cabo por Francesco de Castro, había sido publicada antes por Ferdinando Pisarri (Bolonia, 1713).

${ }^{4}$ En adelante, $I C$. He manejado el ejemplar depositado en la Biblioteca Marciana de Venecia (Sign.: 58/C/42). Este volumen, en aceptable estado de conservación, carece de apostillas y ex-libris. 
cas, adquirirá mayor prestancia estética, tal vez como consecuencia del favor con el que los lectores italianos acogieron la obra ${ }^{5}$.

Giovanni Pietro Cattaneo firmó la traducción ${ }^{6}$. Cuando Cattaneo decidió publicarla, ya otra obra de Gracián, el Oráculo manual, había sido vertida por mano anónima a la lengua italiana gozando en la península de un discreto éxito editorial. Sin embargo, Cattaneo, que antepuso a $I C$ un prólogo mantenido en ediciones posteriores, no hizo mención de traducciones precedentes de la obra de Gracián.

Bajo una consideración formal del texto son pocas las diferencias entre la obra original y su correspondiente versión italiana. Desde el título impreso en el frontispicio se hace patente la conservación del orden tripartita del texto original: $I l \mid$ Criticon | ovvero | Regole della Vita Politica-Morale | di don |Lorenzo Grazian. | Traduzione dallo Spagnuolo in Italiano | di Gio[vanni] Pietro Cattaneo | Divisa in tre Parti; | I. La Primavera della Fanciullezza. | II. L'Estate della Gioventù. | III. L'Inverno della Vecchiaia. Como se advierte de inmediato, hay una ligera variante en la distribución de los epígrafes para cada una de estas partes ${ }^{7}$, que Gracián había organizado de acuerdo con las cuatro edades del hombre uniendo las dos iniciales: "En la primavera de la niñez y en el estío de la juventud"; "Juiciosa cortesana filoso-

5 Tengo noticia de las siguientes ediciones venecianas: 1685, 1698, 1709, 1720, 1730 y 1745 (véase Evaristo Correa Calderón, Baltasar Gracián. Su vida y su obra, Gredos, Madrid, 1970, pp. 305-306 y 354). Para nuestro estudio me he servido de la edición de 1730, de la que proceden las citas salvo indicación contraria. En concreto, del ejemplar depositado en la Biblioteca Attilio Hortis de Trieste (Sign.: 2-2231), procedente de la Biblioteca del Ginnasio Comunale. Esta quinta edición es un manejable volumen cuya hoja de guarda el impresor ha embellecido con un grabado.

${ }^{6}$ No dispongo de noticias biográficas sobre Giovanni Pietro Cattaneo. El Dizionario Biografico degli Italiani (Enciclopedia Italiana, Roma, 1960) nada dice de él; tampoco lo menciona el riguroso Letteratura italiana. Gli Autori. Dizionario bio-bibliografico e indici (Giulio Einaudi Editore, Torino, 19901991; en adelante, DBI). Felice Gambin, "La traduzione come servizio. In margine alla prima edizione italiana del Criticón", QLLS, 20 (1995), p. 141, n. 24, da noticia de un Giovanni Pietro, vástago de la familia bergamasca Cattaneo, el cual mudó al parecer su residencia a Pordenone. A ello se une el silencio de la crítica respecto a $I C$, versión a la que Arturo Farinelli, "Baltasar Gracián. Estudio crítico”, en Baltasar Gracián, El héroe. El Discreto, Rodríguez Serra, Madrid, [1896] 1900, p. 253, n. 2, reservó un juicio severo.

7 Así no sólo en el título, sino también encabezando cada una de las partes que en la traducción italiana. Están respectivamente en pp. 1, 160 y 319 . 
fía en el otoño de la varonil edad"; "En el invierno de la vejez". En el prólogo de la edición italiana no se exponen los motivos por los que el traductor o el impresor han procedido a dicha alteración.

Una alteración que no comporta mayores cambios, ya que para cada una de estas tres partes se ha mantenido el número y orden de los capítulos o crisis, helenismo que Cattaneo reemplaza con la voz italiana discorso ${ }^{8}$. Se omiten tan sólo la dedicatoria a don Pablo de Parada y la advertencia inicial a los lectores de la obra.

Hay que señalar que el tipógrafo Pezzana desestimó la utilidad de las palabras resaltadas en los márgenes ${ }^{9}$, que tanto facilitaban la consulta del texto y que constituían una práctica aún corriente en las artes de impresión de la época, incluso en Italia.

Cattaneo no proporciona en el prólogo indicaciones sobre la edición castellana que está traduciendo. Si limitamos a la primera parte el estudio de las variantes para su comparación con la versión italiana, observaremos significativas afinidades con las ediciones precedentes a 1658. A continuación, escojo algunos ejemplos, cuyas lecturas afines o discordantes realzo con cursivas ${ }^{10}$ : "dissipando a cento, e a cento, ciò ch'egli avea accumulato ad uno, ad uno" (p. 33) $\leftarrow$ "desperdiciando [1658: despreciando] ciento a ciento lo que él recogió uno a uno" (p. 122); "Restato allora più libero, e meno assistito" (p. 34) $\leftarrow$ "quedando [1658: quando] yo más libre y menos triste" (p. 123); "restammo egli morto, ed io prigioniero" (p. 35) $\leftarrow$ "Quedó él tendido [1658: rendido] y yo preso" (p. 125); "i tesori dell' osservazioni curiose" (p. 107) $\leftarrow$ "los tesoros de la observación [1658: observancia] curiosa" (p. 241); "Non solo le pietre non attraevano gli

${ }^{8}$ Dicc. Aut., s. v. crisis: "Juicio que se hace sobre alguna cosa, en fuerza de lo que se ha observado y reconocido acerca de ella". Añado de paso que con esp. discurso designa Gracián cada uno de los capítulos de su Agudeza y arte del ingenio (Madrid, 1642).

${ }^{9}$ Dichas acotaciones son frecuentes en las dos partes iniciales de las primeras ediciones españolas de $E C$. No así en su tercera parte, donde los márgenes quedaron en blanco por voluntad expresa de Gracián para que de ese modo el lector pudiera anotar el texto; véase Aurora EgIDO, "Sobre una traducción al italiano de la Agudeza", en La rosa del silencio. Estudios sobre Gracián, Alianza, Madrid, [1987] 1996, p. 216.

${ }^{10}$ Las citas proceden de la edición veneciana de 1730, entre paréntesis indico el número de página. Para la correspondiente española, se cita de $E C$ según la ed. de Evaristo Correa Calderón. Advierto que en este trabajo considero sólo la Primera parte de la obra de Gracián. 
ospiti" (p. 115) $\leftarrow$ "No sólo no atraían [1658: traían] las piedras a los huéspedes" (p. 256); "Facilmente, rispose" (p. 116) $\leftarrow$ "Fácilmente [1658: Finalmente] -respondió” (p. 258).

\section{Prólogo del traductor}

Un prólogo al lector precede la versión italiana ${ }^{11}$. Estas páginas preliminares me interesan porque en ellas Cattaneo, además de hacer uso de las consabidas fórmulas de modestia y de exponer los motivos que le han inducido a verter al italiano la obra magna de Gracián, enumera los criterios con los que se ha regido para tarea tan difícil.

Se trata de una traducción ad sensum, tal como advierte Cattaneo: "L'ho tradotto fedelmente conforme il senso di esso" (p. iv). Una declaración que ya no sorprende en la Italia de fines de siglo xVII, donde una consolidada tradición humanística ha aquilatado la pericia de los traductores a la lengua vernácula por lo menos desde la centuria anterior ${ }^{12}$.

La lengua y el estilo de Gracián mal hubieran tolerado, por lo demás, una traducción servil. La sucesión ininterrumpida de juegos de palabras manieristas, con el recurso a la dilogía, al calambur o a la paronomasia, habría impedido el automatismo en el trabajo del traductor. El hecho de que a menudo el pensamiento de Gracián se encuentre entretejido con la expresión aguda $^{13}$ constituye, por otro lado, un desafío a las artes interpretativas y de escritura del traductor italiano quien, en no pocas ocasiones, se ve forzado a emular la creatividad del jesuita.

11 Véase Gambin, art. cit.

${ }^{12}$ Las únicas traducciones ad verbum que recordamos haber visto en el siglo Xvir son las de autores de la Antigüedad clásica cuyo texto original se acompaña, con estricta finalidad didáctica, de una versión italiana literal de una segunda acomodada al sentido (cf. Virgilio, L'Opere cioè la Bucolica, la Georgica e l'Eneide commentate in lingua volgare toscana da G. Fabrini, C. Malatesta e F. Venuti, Sessa, Venezia, 1615), la cual corresponde por cierto a una tradición que llega hasta nuestros días. Cf. Gianfranco Folena, Volgarizzare e tradurre, Giulio Einaudi, Torino, [1973] 1994, pp. 50-53.

13 Algo que A. Egido, art. cit., p. 213 define asimismo con agudeza: "La unión de res y verba, de forma y acción, ornamento y sustancia, andan parejas en la prosa gracianesca que sigue en ello las reglas del decoro de la retórica clásica, concediendo a la agudeza un valor estratégico y práctico al mismo tiempo". 
Si la actitud adoptada por Cattaneo frente a la labor de traducción es por regla general la que esperábamos, más sorprendente es en cambio el cuidado que revela al exponer los criterios de que se ha valido para afrontar las dificultades derivadas de dicha tarea y que, en casos extremos, ha provocado una transformación desenfadada del texto original. Desarrollaré en la parte final de este trabajo cada una de estas manipulaciones por separado $(\S 6)$, limitándome por ahora a exponer las advertencias al lector en el mismo orden en el que Cattaneo las enumera. Éstas son: eliminación de las menciones locales, reemplazadas por alusiones a personajes y episodios de alcance universal; reducción de pasajes por condicionamientos formales o en favor de soltura narrativa; adiciones hilvanadas por el traductor para mayor confirmación de las tesis de Gracián.

Frente a la desenvoltura con la que Cattaneo se enfrenta en tales ocasiones a la obra que traduce, contrasta su manifiesta preocupación por la lengua. En el prólogo, donde confiesa con modestia sus escasos conocimientos del español, declara haberse servido de las obras lexicográficas corrientes en la Italia de fines del siglo xvII. La vaga alusión al "Dizionario del Franciosini, quale benchè il più copioso di quanti ne siano alle stampe" (p. iv) encubre el auxilio de Lorenzo Franciosini, Vocabolario italiano e spagnolo, spagnolo e italiano (Roma, 1620) ${ }^{14}$. Admite haber contado ocasionalmente con el asesoramiento tanto de italianos conocedores de la lengua española, como de individuos de la nación hispana. Uno de estos españoles residentes o de paso por el territorio de la Serenissima habría leído la traducción, juzgándola con una valoración halagüeña a la que Cattaneo da cabida en su prólogo: "ho ottenuto il mio fine di tradurlo, come mi disse uno spagnuolo, sin medio" (p. v).

Es banal la argumentación con la que el traductor italiano justifica la empresa que ha acometido, al parecer obedeciendo a los ruegos de una dama que habría quedado sugestionada

${ }^{14}$ He tenido a mano la edición veneciana de 1796. Lorenzo Franciosini fue autor asimismo de una Grammatica spagnuola ed italiana (Venecia, 1624) y traductor de El Quijote (Venecia, 1622-1625). Véanse Alfonso D’Agostino, "L'apporto spagnolo, portoghese e catalano", en Storia della lingua italiana. III, eds. Luca Serianni y Pietro Trifone, Einaudi, Torino, 1994, p. 809, y Margherita Morreale, Un contributo italiano recente allo studio della lingua spagnola, Consejería de Educación-Embajada de España, Roma, 1994, p. 28 y la nota de STEFANIA del Bravo en DBI, s. v. 
por el dictamen favorable de Cattaneo tras la lectura de la obra magna de Gracián. El hecho de que en el prólogo no se haga explícita la identidad de tal dama induce a pensar que el autor de la versión italiana ha echado mano de una convención, a menos que motivos de puro orden galante impusieran el anonimato de la interlocutora de tan eruditos coloquios.

\section{ESTILO MANIERISTA}

Las mayores dificultades que Cattaneo tuvo que superar, llegada la hora de verter al italiano el texto de $E C$, derivaban de la complejidad del lenguaje de Gracián, cuya irrefrenable agudeza supone un reto a las aptitudes del traductor. Es un escollo que a menudo se revela insuperable, y ante el cual reconoce Cattaneo sus limitaciones para poder trasladar a su lengua el ingenioso entramado retórico, tal como confiesa con autocrítica en el prólogo al lector:

Molti bisticci e proverbi, che per gli equivoci della lingua spagnuola sono bellissimi nel loro idioma, non si sono potuti tradurre con la stessa vivezza nel nostro. Onde mi sono ingegnato d'imitarli più che sia stato possibile, o almeno circoscriverli con la maggior diligenza che m'ha permesso la mia debole capacità (pp. iv-v).

Examino a continuación los medios de los que Cattaneo se sirve para soslayar las principales dificultades retóricas y estilísticas.

3.1. La paronomasia o annominación. La semejanza entre ambas lenguas románicas facilita en algunas ocasiones la conservación del juego verbal. Así ocurre con el recurso a la paronomasia, cuyo artificio consiste, como define Gracián, en "trocar alguna letra o sílaba de la palabra, o nombre, para sacarla a otra significación"15. Cattaneo a veces consigue trasvasar la paronomasia a su versión italiana: "Veggio, disse, alcune montagne volanti, quattro alati mostri marini, se non sono nubi naviganti. No, sono navi, disse Critilo" (p. 29) Ł "Veo - dijo éste-unas montañas que vuelan,

15 Véase "Discurso 32", Agudeza y arte de ingenio, en Obras completas, ed. Arturo del Hoyo, 3a ed., Aguilar, Madrid, 1967, p. 393. 
cuatro alados monstruos marinos, si no son nubes, que navegan. -No son sino naves - dijo Critilo" (p. 115); "che chi è saggio bramerà di fare breve il passaggio dalla culla alla tomba, dal tálamo al tumulo" (p. 40) $\leftarrow$ "pero un desengañado tomara antes haber sido trasladado de la cuna a la urna, del tálamo al túmulo" (p. 132); "ora principi a vivere, andrai a bell'agio, vivendo e vedendo" (p.42) $\leftarrow$ "Ahora comienzas a vivir; irás viviendoy viendo" (p. 134); "non cedendo l'uno all'altro alcun vizio di valere e valore" (p. 65) $\leftarrow$ "no queriendo ceder ningún vicio esta ventaja del valor y del valer" (p. 173); "In questa guisa sconvolse tutte le cose ed i casi" (p. 124) $\leftarrow$ "Desta suerte fue barajando todas las cosas y casos" (p. 271). En algún caso la versión italiana incluso supera al modelo: "da quella parte sembrava non facciata, ma sfacciata" (p. 115) $\leftarrow$ "parecía por esta parte, no fachada, sino echada" (p. 256).

Aún en situaciones extremas, advertimos por parte del traductor una preocupación que le lleva a emular la pluma de Gracián. Considérense las palabras con las que Andrenio describe su delicada situación tras el terremoto: "mi stimai esser lunghi da me medesimo, dalla tema atterrito, dalle pietre atterrato" (p. 10) $\leftarrow$ "halléme perdido de mí mismo, muerto y aun sepultado entre peñas y entre penas" (p. 88). En la traducción de dicha frase Cattaneo, no pudiendo mantener el juego paronomástico de los sustantivos esp. peña - pena, traslada la annominación a los verbos ital. atterrire - atterrare sin que haya una sustancial divergencia de contenido: "dalla tema atterrito" ('aterrorizado por el miedo') $\leftarrow$ "[sepultado] entre penas"; "dalle pietre atterrato" ("abatido por las piedras') $\leftarrow$ "sepultado entre peñas". Considérese asimismo "onde risolse, per uscir di pene, uscir di vita" (p. 121) $\leftarrow$ "tomó por partido despeñarse para despenarse" (p. 265), donde Cattaneo suple con el paralelismo de la construcción sintáctica la imposibilidad de mantener el juego paronomástico.

Frente a estos ejemplos, que ilustran el compromiso en la mecánica de la traducción, abundan los casos en los que su trasvase al italiano se hace imposible. Por citar algunos: "e talora, senza parlar, il richiesi a me stesso" (p. 5) ६ "Qué de veces, y sin voces, me lo pregunté a mí mismo" (p. 81); "e perciò tra loro differentissimi ciascuno opra a suo genio" (p. 30) $\leftarrow$ "y así todos parecen diferentes, cada uno de su gesto y de su gusto" (p. 117); "suscitò un incendio tale, che lo ridusse in cenere, privo ad un tratto di vita e di Regno" (p. 47) $\leftarrow$ "tantos vapores quiso levantar en tributos, que lo abrasó todo, perdiendo el mundo y el mando" (p. 141). 
Son pocos, proporcionalmente, los casos en los que Cattaneo elude la annominación aun pudiendo mantener en su versión el recurso estilístico: "tanto poggiò in alto che mancandogli l' ale precipitò, con sue chimere, nel mare di un doloroso pianto, che fu un nulla, ma di tormento in tormento" (p. 47) $\leftarrow$ "tanto quiso adelgazar, que le mintieron las plumas y dio con sus quimeras en el mar de un común y amargo llanto: que va poco de pennas a penas" (pp. 141-142); "narravano tutti cose prodigiose" (p. 82) $\leftarrow$ "Contaban todos cosas y casos portentosos" (p. 204); "Che casa è stata questa, dicea Critilo?" (p. 120) $\leftarrow$ “¿Qué cosa y qué casa ha sido esta? -decía Critilo" (p. 263).

En el recurso a la paronomasia de Gracián puede estribar el motivo que ha desviado al traductor de la correcta interpretación de algunos fragmentos: "per accrescere maggiormente tormenti a tormenti" (p. 32) $\leftarrow$ "para que se doblase su tormento con la tormenta" (p. 121); "come quegli altri, ch'avendola [la spalla], si fanno rispettare e temere" (p. 61) $\leftarrow$ "como aquellos que van allí cargados dellas [de espaldas], con más cargas a más cargos" (p. 165).

3.2. La derivación. De modo parecido se comporta Cattaneo frente a la derivación. Mantiene dicha figura en los pocos casos en los que hacerlo no comporta grandes dificultades en el trasvase a una lengua de la misma familia: "senza però cessare di mirarlo ed ammirarlo" (p.3) $\leftarrow$ "no cesando de mirarle y de admirarle" (p. 79); "che vendi? Tutto ciò ch'è nel mondo e senza prezzo, perchè con disprezzar il tutto sarai padrone del tutto" (p. 152) $\leftarrow$ "-Pues ¿qué vendéis? -Todo cuanto hay en el mundo. - ¿Y sin precio? -Sí, porque con desprecio: despreciando cuanto hay, seréis señor de todo" (p. 318). Sólo en una ocasión llama la atención el hecho de que, pudiendo conservar el artificio derivativo en la versión italiana, Cattaneo ignore el procedimiento: "cominciasegli a cantare canzoni per addormentarlo" (p. 79) $\leftarrow$ "Comiénzanle a cantary encantar con falsedades" (p. 198), donde pudo haber recurrido al doblete ital. cantare / incantare.

En la mayor parte de los casos el traductor italiano se ve imposibilitado a verter el texto de Gracián a su propia lengua, manteniendo el procedimiento retórico. Así, aunque español e italiano comparten el sustantivo borra por proceder en ambos idiomas del latín tardío bŭrra ('lana grosera'), y como por su parte el español ha generado a partir de esta voz el verbo bo- 
$\operatorname{rrar}^{16}$ mientras que el italiano mantiene aún hoy el latinismo cancellare, Cattaneo opta por ignorar el artificio: "che d'uomo non hanno altro che l' apparenza, e nel resto borra ed illusioni" (p. 30) $\leftarrow$ "que no tienen más que el pellejo y todo lo demás borra y así son hombres borrados" (p. 117).

Por otro lado, considérese el esfuerzo de Cattaneo que, enfrentado a la imposibilidad de mantener en la versión italiana el juego de voces en el que se basa el fragmento que reproduzco a continuación, emula con otras artes la pericia retórica del aragonés: "Alcuni parlavano col naso, sebbene non mancava chi gli conoscesse al naso" (p. 71) $\leftarrow$ "Algunos hablaban gangoso, si bien no faltaba quien les entendía la ganga" (p. 185). El testimonio de Covarrubias nos ayuda a entender el pasaje del texto original, pues el lexicógrafo escribe, s. v. gangoso: "El que habla por las narizes, con voz como la de ganga"17; y s. v. ganga: "Es un cierto género de ave palustre, dicha assí por el sonido de la voz". El traductor italiano, que interpreta correctamente ital. parlare col naso $\leftarrow$ esp. hablar gangoso, engarza acto seguido el giro ital. conoscere (qualcuno) al naso ('conocer a alguien por la nariz'), lo que le permite el juego repetitivo del sustantivo. Agrego que con esta equivalencia Cattaneo demuestra su fidelidad a Franciosini (que por otro lado parece hacerse eco de Covarrubias), donde leemos s. v. gangoso: "colui che parla col naso".

3.3. El equívoco. Uno de los aspectos léxicos más llamativos de la agudeza verbal de los autores representativos del barroco español es el artificio derivado del empleo simultáneo de las diversas acepciones de voces polisémicas ${ }^{18}$. Es obvio que, salvo en casos excepcionales, sólo con dificultad este juego de palabras podrá ser vertido a otra lengua.

En la obra de Gracián se dan con insistencia algunas de estas palabras polisémicas. Limitándome a la primera parte de $E C$, advierto el empleo del esp. yerro (o hierro) en la doble acep-

16 Véase Joan Corominas, y José Antonio Pascual, Diccionario crítico etimológico castellano e hispánico, Gredos, Madrid, 1980-1991, s. v. borra y borrar. En adelante, $D C E C H$.

17 Vaíllo, en su ed. de EC, anota: "El hablar gangoso se atribuía a los enfermos del mal francés o sífilis, que destruía los cartílagos, como la nariz" (p. 185, n. 1).

18 Remito al "Discurso 33", Agudeza y arte de ingenio, en Obras completas, pp. 396-402. 
ción ya ilustrada, en artículos separados, por Covarrubias, s. v. hierro: "Por el metal" (\$1) y "por pecado, delito o horror, error" (\$ 2). La alusión simultánea a ambas acepciones de dicha voz la registramos en más de un caso: "dicesi ch'avesse il petto guarnito d'acciaio, ma io dico ch'avea petto e cuore rivestiti non men di ferro che d'errori" (p. 2) $\leftarrow$ "Vestido dicen que tuvo el pecho de aceros, mas yo digo que revestido de yerros" (p. 76); "mi condussero tantosto in un tetro carcere, caricandomi di ferro, frutto condegno degli errori da me commessi col ferro" (p. 35) $\leftarrow$ "Dieron luego conmigo en un calabozo, cargándome de hierros, que éste fue el fruto de los míos" (p. 125).

La primera observación que se desprende de la lectura de estos tres pasajes, que cotejo con la respectiva traducción al italiano, es que Cattaneo advirtió el juego de palabras que en ellos subyace. Aunque no puede perpetuar en su lengua la polisemia de esp. (y)erro mediante ital. ferro, opta sin embargo por mantener dicha voz como referente del metal, al tiempo que incorpora una segunda voz ital. errore (en cuyo caso estamos muy cerca de la paronomasia) portadora de la segunda de las acepciones ilustradas por Covarrubias.

Sólo en un caso Cattaneo se aparta de esta solución de compromiso prefiriendo una reelaboración completa de la frase: "Lasciavasi di gran lunga addietro la Casa d'Oro di Nerone, qual pretese coll'oro ricoprire la ruggine de' suoi misfatti" (pp. 113-114) $\leftarrow$ "Dejaba muy atrás la casa de oro de Nerón, con que quiso dorar los yerros de sus aceros" (p. 253). Aquí el traductor ha vertido menos literalmente que en los anteriores ejemplos con ital. ruggine ('orín, óxido') / misfatto $\leftarrow$ esp. yerro, mediante una argucia que, aunque no le impide tener que hacer recurso una vez más a dos sustantivos italianos, revela mayor acomodación a la lengua receptora.

Por otro lado no es infrecuente que Cattaneo ignore uno de los significados, simplificando al máximo la versión (véase n. 25): "i cavalli che la tiravano [la carrozza] erano due serpenti, ed una volpe era il carrozziero" (p. 67) $\leftarrow$ "las pías ${ }^{19}$ que la

19 Dicc. Aut., s. v. pía: "El caballo u yegua, cuya piel es manchada de varios colores, como a remiendo" [es acepción que se ilustra con la autoridad de este mismo pasaje de EC]. Cf. Lorenzo Franciosini, Vocabolario italiano e spagnolo. Vocabolario español e italiano, Stamperia Baglioni, Venezia, [1620] 1796, s. v.: "una chinea, o sorte di cavalletto pezzato, cioè di molti colori, o di differente pelame, che soglion venire dall'Isole Settentrionali", donde 
tiraban, más remendadas que pías, eran dos serpientes, y el cochero una vulpeja" (p. 177); "gli promisero per una notte che mai oscurò" (p. 80) $\leftarrow$ "ofreciéronle que sí una tarde, que, sin llegar, siempre lo fue” (p. 199).

Ni siquiera ante una voz polisémica como esp. esposas (ital. spose y manette), de tanta fortuna en los juegos de ingenio verbal, consigue Cattaneo encontrar una solución aceptable, por lo que simplifica al máximo el pasaje: "Gridava uno: Qui si vendono spose: Qual'è il prezzo? Nulla, ed anche meno" (p. 158) $\leftarrow$ "Pregonaba uno: - «Aquí se venden esposas!» Llegaban unos y otros preguntando si eran de hierro o mujeres. - «Todo es uno, que todas son prisiones». - ¿iY el precio?». -«De balde, y aun menos»" (p. 328).

3.4. Iunctura y divisio (calambur). En orden progresivo de dificultad verbal encontramos la figura retórica del calambur, que se verifica cuando "las sílabas de una o más palabras, agrupadas de otro modo, producen o sugieren un sentido radicalmente diverso" 20 . Es tropo en el que el ingenio y la agudeza se encuentran quintaesenciadas, lo que equivale a un enorme desafío para quien debe trasladar a otra lengua, por afín que ésta sea, un texto con tales características.

Cattaneo, ante los casos de iunctura y divisio que hemos identificado en esta primera parte de $E C$, opta por ignorar esta figura en su versión italiana: "Lo stesso succede a quell'altro, che similmente viene a cavallo per distruggere il tutto" (p. 62) $\leftarrow$ "Lo mismo sienten todos de aquel otro, que también viene a caballo para acaballo todo" (p. 167); "Ora dico, soggiunse Critilo, che con ragione chiamasi cuore, esprimendo con esso il suo carico, ch'è l'esser pensieroso" (p. 103) $\leftarrow$ "Ahora digo -ponderó Critilo-que con razón se llama corazón, que exprime «el cuidadoso»" (p. 236). La omisión, por la imposibilidad de trasvasar el juego de palabras a la lengua receptora, conjugada con la fidelidad al original, causa en ambos casos pasajes sin sentido: el lector italiano difícilmente comprenderá por qué

una vez más advertimos las huellas de SEBASTIÁn de CovarRubias (Tesoro de la lengua castellana o española, ed. Martín de Riquer, Alta Fulla, Barcelona, 1987, s. v.: "Haca remendada; vienen de las islas setentrionales, para servicio de los reyes y grandes señores").

${ }^{20}$ Es definición de Fernando Lázaro Carreter en su Diccionario de términos filológicos, Gredos, Madrid, 1962, s. v. calambur. 
tiene que venir a caballo para destruirlo todo; o por qué el corazón (ital. cuore) se llama así 'con todo motivo'.

En un caso Gracián recurre a la formación de un neologismo, la voz simplato que opone al sintagma esp. sin plato, lo que agrava aún más la posición de nuestro traductor (véase § 3.6). Este interpreta a su modo el difícil pasaje: "furono portati molti piatti, benchè molti mangino in pugno ad uso de' sparvieri" (p. 77) $\leftarrow$ "Sacaron muchos platos, aunque los más comen simplato" (p. 195). Agregamos que es confuso el significado de dicho neologismo, para el que M. Romera Navarro, en su edición, postuló: "Cabe entenderlo como imaginario alimento propio de los simples o simplazos"21.

3.5. La antítesis. La contraposición de voces de significado antitético es otro más de los rasgos característicos de la escritura de Gracián ${ }^{22}$. Entronca a su vez con el gusto por la paradoja conceptista apreciada por los lectores del barroco y no sólo hispánico.

En numerosas ocasiones la antítesis aparece imbricada con otros procedimientos retóricos, tales como el recurso a voces polisémicas o a la derivación, ganando en artificiosidad e ingenio y dificultando de ese modo la tarea del traductor. Leamos el siguiente pasaje según la versión de Cattaneo, contraponiéndolo a la originalidad de expresión del texto de Gracián: "perchè dunque altri non sono divenuti simiglianti nelle virtù, disse Critilo? Perchè non hanno voluto" (p. 52) $\leftarrow$ " ¿¿cómo no se han hecho [héroes]?» - preguntó Critilo. - «Porque se han deshecho»" (p. 150). Aunque en su lengua se le ofrecía asimismo el doblete ital. farsi/disfarsi, el traductor era consciente de que no podía emplear esta segunda para contraponerlo a ital. farsi eroe (preferible ital. diventare e.), pues el sentido exigiría las voces ital. sciogliersi, squagliarsi u otras afines.

Cattaneo sacrifica, en definitiva, la literalidad de la versión en favor de un texto traducido que pueda ser leído con naturalidad por el público italiano. Ello es tanto más evidente en los dos ejemplos que facilito acto seguido, por medio de los cuales se advierte el esfuerzo interpretativo del traductor: "ivi si trova tutto il mondo, ove tutti sperano gran cose e nulla ottengono"

${ }^{21}$ Cf. la ed. de Correa Calderón, Espasa-Calpe, Barcelona, 1971, p. 111, n. $\operatorname{ad} 1.20$.

22 Véase "Discurso 42", Agudeza y arte de ingenio, en Obras completas, pp. $429-432$. 
(p. 84) $\leftarrow$ "ahí perece el mundo entero y todos acaban porque no acaban" (p. 207) 23; "e già attoniti non tentarono d'incendiare il palazzo, come aveano determinato" (p. 107) $\leftarrow$ "y ya helados, no trataron de pegar fuego al palacio, como lo intentaban" (p. 241).

3.6. El recurso al neologismo y a los préstamos léxicos. Algunos de los juegos verbales salidos de la pluma de Gracián culminan con la creación de palabras acuñadas por el jesuita aragonés o con la inclusión, en el texto español, de préstamos léxicos de otras lenguas, principalmente del latín, insertos en el texto con la finalidad de explotar sus afinidades fonéticas con la lengua castellana.

En el primer caso la semejanza entre español e italiano permite a Cattaneo emular el estilo del texto original que está traduciendo, afinando sus facultades creativas: "un giudice, a cui si veggano unte le mani, tosto d'auditore vien tenuto toccatore" (pp. 149-150) $\leftarrow$ "al juez que le hallamos las manos untadas, luego le condenamos de oidor a tocador" (p. 313). Al igual que esp. juez y oidor, ital. giudice y auditore son voces sinónimas, la segunda de las cuales (derivada de lat. audītor) sugiere la semejanza fonética con el verbo ital. udire ('oír'). De ahí al empleo, a renglón seguido, de ital. toccatore $\leftarrow$ esp. tocador, el paso es breve.

Mayores son las dificultades con las que Cattaneo tropieza llegada la hora de traducir el siguiente pasaje, en el que Gracián reelabora la toponimia de la capital: "pochi [entrano] per lava piedi, molti per untamani" (p. 110) $\leftarrow$ "pocos [entran] por Lavapiés y muchos por untamanos" (p. 246). En la versión italiana el topónimo correspondiente al barrio madrileño de Lavapiés es "traducido" con la finalidad de poder contraponerle la voz ital. untamani $\leftarrow$ esp. untamanos, topónimo imaginario que remite a quienes con lisonjas y obsequios aspiran a conquistarse un puesto en la Corte.

Cuando Gracián engloba en su redacción préstamos latinos lo hace por lo general al hilo de las posibilidades fonéticas que dichas voces le brindan en pos de la agudeza verbal. En tales casos, el traductor se ve obligado a sacrificar el artificio en

${ }^{23}$ El sentido del pasaje es poco claro. Norberto Cuesta Dutari sugiere: "y todos acaban porque no acá-van" ("Para un texto más correcto de El Criticón”, BBMP, 30, 1955, p. 34). 
aras de la interpretación. Considérese el tino con el que Cattaneo resuelve el siguiente pasaje: "scoperto un pasticcio non v'era dentro cos'alcuna, il presciutto era solo un osso rancido" (p. 78) $\leftarrow$ "al descoronar la empanada, hallaba sólo el eco, y del pernil el nihil" (p. 196). Si bien la voz latina conserva en el contexto español su valor adverbial originario ('no quedaba nada'), Gracián la emplea por motivos formales ya que en ella se repiten los fonemas finales de esp. pernil del que, como arguye nuestro jesuita, el adverbio latino es "sólo el eco". Nos parece difícil poner objeciones a la fórmula encontrada por Cattaneo, que también en el caso presente da con una solución acertada a una dificultad de traducción que se presentaba insoluble.

\section{Sentenciosidad Paremiológica}

En la orilla opuesta del artificio manierista cabría disponer el material paremiológico al que recurre Gracián, si no fuera porque en multitud de ocasiones emula la condensación de los proverbios populares en pos de un estilo sentencioso que no excluye la paradoja (cf. "el muy derecho es tuerto", p. 96). Lo que atrae a Gracián no es por tanto lo sencillo del refrán, sino su valor ambivalente; recurre a él tergiversándolo en pos de expresividad $^{24}$.

Gracián encuentra inspiración en el refranero tradicional, pero también engarza en el texto frases con resabio sapiencial acuñadas por él. Limitándome a la primera parte de $E C$, es conocido el siguiente fragmento que confronto con la traducción de Cattaneo, para lo que dispongo ambas versiones en columnas paralelas:

Quando vedesi uno, che presume di saper assai, lo creda un ignorante, tenga il ricco per povero de' veri beni. Chi a tutti comanda, è schiavo universale. Chi è grande di statura non è più uomo degli altri, il grosso ha poca sustanza, chi
Cuando vieres un presumido de sabio, cree que es un necio; ten al rico por pobre de los verdaderos bienes; el que a todos manda es esclavo común; el grande de cuerpo no es muy hombre; el grueso tiene poca sustancia; el que hace el 
fà il sordo, sente più di quello che si vorria, chi guarda con lindura, o è cieco, o presto acciecherassi, chi porta seco odori, non rende a tutti buon odore di sè stesso; il gran parlatore non dice cosa che vaglia, chi ride inganna, il mormoratore condanna sè stesso, chi più mangia meno mangia, taluno par che burli, e si confessa, chi biasma vuol comprare, chi fà il semplice è più scaltrito degli altri; a chi nulla manca, manca egli a se stesso, all'avaro tanto serve quello che possiede, quanto quello che non possiede, chi dice più ragioni ne ha meno, il più savio per il più è meno inteso, far vita sovverchiamente lauta è un voler morir presto, chi ama la vita l'odia, chi ti adula ti biasma, chi t'accarezza più del solito ti vuol tradire, nelle buone opinioni v'è spesso ignoranza, il sovverchio diritto è torto, il troppo bene fà male; per abbreviar la strada talora s'allunga, per non perder un boccone, se ne perdono cento, chi guadagna poco, e spesso, guadagna al doppio degli altri, chi ti fa piangere ti vuol bene, ed in fine: Chi affetta, e brama di parere, è meno assai di quello che pare (pp. 66-67). sordo oye más de lo que querría; el que mira lindamente es ciego o cegará; el que huele mucho huele mal a todos; el hablador no dice cosa; el que ríe, regaña; el que murmura, se condena; el que come más, come menos; el que se burla, tal vez se confiesa; el que dice mal de la mercadería, la quiere; el que hace el simple, sabe más; al que nada le falta, él se falta a sí mismo; al avaro, tanto le sirve lo que tiene, como lo que no tiene; el que gasta más razones, tiene menos; el más sabio suele ser menos entendido; darse buena vida es acabar; el que la ama, la aborrece; el que te unta los cascos, ése te los quiebra; el que te hace fiestas, te ayuna; la necedad la hallarás de ordinario en los buenos pareceres; el muy derecho es tuerto; el mucho bien hace mal; el que escusa pasos, da más; por no perder un bocado se pierden ciento; el que gasta poco gasta doblado; el que te hace llorar te quiere bien; $y$, al fin, lo que uno afecta y quiere parecer, eso es menos (pp. 175-177).

En este pasaje, Gracián encadena de manera ininterrumpida sentencias proverbiales, sumando a los refranes tradicionales otros creados por él, los cuales constituyen el grueso de la recopilación. Entre los primeros registro "el que come más, come menos" 25 , "el que te hace llorar te quiere bien" 26 y "el que se

25 GonZalo Correas, Vocabulario de refranes y frases proverbiales, Tip. de la "Rev. de Archivos, Bibliotecas y Museos", Madrid, [h. 1627] 1924, véase nota de Vaíllo a EC, p. 111, n. 1.

26 Augusto Arthaber, Dizionario comparato di proverbi e modi proverbiali, Ulrico Hoepli Editore, Milano, 1952, § 245; cf. "Quien tiene amores tiene 
burla tal vez se confiesa" 27 , a los que cabe agregar otros que si bien no hemos podido documentar en las consabidas colecciones paremiológicas, por lo menos con la misma lectura transmitida por Gracián, sí revelan en cambio mucha semejanza con refranes del repertorio tradicional: "Cuando vieres un presumido de sabio, cree que es un necio"28; "el que murmura se condena"29; "el que dice mal de la mercadería la quiere"30; "el que hace el simple sabe más"31; "el que gasta más razones tiene menos" 32 ; "el que te hace fiestas, te ayuna" 33 ; "el muy derecho es tuerto" 34 ; "el mucho bien hace mal" 35 ; "lo que uno afecta y quiere parecer, eso es menos" 36 .

La sensación que se tiene tras la lectura del fragmento de Gracián es la de que, con esta caótica enumeración, sin orden ni concierto, nuestro autor pretendió burlarse y censurar a lo cervantino la costumbre de quienes recurren de continuo a las fórmulas lexicalizadas y ensalzan de modo desmesurado la pretendida sabiduría que en ellas incuba. Pero lo que me importa aquí es analizar la perspicacia de Cattaneo para verter a su lengua estas fórmulas lexicalizadas de no siempre clara interpretación.

En este pasaje, como en general a lo largo de toda la versión italiana, uno de los rasgos más perceptibles en la labor de

dolores" (Mal Lara en LuIS MARTínez KLEISER, Refranero general ideológico espanol, Hernando, Madrid, 1989, § 3.810).

27 G. Correas, en Martínez Kueiser, op. cit., § 8.026; véase nota de Vaíllo a $E C$, p. 111, n. 4.

28 "A quien presume de sabio, por necio hay que dejarlo" (Mal Lara en MARTínez KLEISER, § 56.796).

29 "Hacia ti acusas cuando murmuras" (Mal Lara en MARTínez KLEISER, § 44.628) y "Quien dice mal, procura su mal" (§ 44.629).

${ }^{30}$ Cf. G. Correas, op. cit., p. 179: "El que dice mal de la yegua (Arthaber, $\S 183$ : de la pera), ése la lleva”.

31 "A veces, el sabio necio parece" (Mal Lara en Martínez Kleiser, § $56.861)$.

32 "Para la plebe, quien más charla más razón tiene" (Mal Lara en MARTÍNEZ KLEISER, § 29.402).

33 Cf. Correas, p. 182: "El que te dice la copla, ése te la nota; o ése te la hace; o ése te la echa" y p. 426: "Quien te hace fiesta que no te suele hacer, o te quiere engañar, o te ha menester".

34 "El hombre rigoroso, a todos se hace odioso" (Mal Lara en Martínez KLEISER, § 57.991).

35 "El bien total es la fuente del mal" (Mal Lara en Martínez KLeiser, § 7.337).

36 "Si los hombres fueran lo que quieren parecer, ¡cuánto mayor sería su valer!” (Mal Lara en MARTínez KLEISER, § 4.538). 
Cattaneo es el esfuerzo por eliminar toda ambigüedad del texto original. Así, por poner tan sólo un ejemplo, el traductor restituye el sustantivo que Gracián omitió tal vez para no incurrir en enojosas repeticiones aun a riesgo de confundir al lector: "far vita sovverchiamente lauta è un voler morir presto; chi ama la vita l'odia" $\leftarrow$ "darse buena vida es acabar; el que la ama la aborrece". En esta misma línea, advertimos la simplicidad en $I C$ de pasajes que, por la fraseología en ellos empleada, eran de más ardua interpretación en el texto original: "chi $t i$ adula ti biasma" $\leftarrow$ "el que te unta los cascos ése te los quiebra" 37 ; "chi t'accarezza più del solito ti vuol tradire" (ital. accarezzare: "adular') $\leftarrow$ "el que te hace fiestas te ayuna".

Pese a la dificultad que entraña la traducción de proverbios, son pocos los errores que registro. Me llama la atención la falsa equivalencia entre ital. guadagnare ('ganar') $\leftarrow$ esp. gastar en: "chi guadagna poco e spesso guadagna al doppio degli altri" $\leftarrow$ "el que gasta poco gasta doblado", donde esperaríamos ital. spendere. En la solución del traductor parece percibirse la interferencia con un refrán de cuño italiano (que equivaldría a 'quien gana poco y a menudo, gana el doble que los demás') que no he conseguido documentar.

Interpreto esp. regañar a la luz de la acepción ilustrada por Covarrubias, s. v.: "Es propio de los perros, quando muestran los dientes y, sin ladrar, hazen cierto sonido con que manifiestan su saña”. De ahí la perplejidad que nos causa la traducción de "chi ride inganna" $\leftarrow$ "el que ríe regaña" 38 .

Para "chi guarda con lindura, o è cieco o presto acciecherassi" $\leftarrow$ "el que mira lindamente es ciego o cegará", además de lo discutible de trasladar ital. con lindura ${ }^{39} \leftarrow$ esp. lindamente, señalo como poco pertinente el valor reflexivo del verbo ital. accecarsi frente a esp. cegar, lo que presupone una víctima propiciatoria para quien finge tener aspecto inofensivo y pacífico.

37 Dicc. Aut., s. v. casco: lavar o untar los cascos: "Phrases que denotan lisongear mucho a uno, alabándole sus acciones con demasía y afectada ponderación"; cf. Franciosini, op. cit., s. v. untar. "Quebrar la caveça, y después untar el casco, romper il capo, e poi ugner il cranio, si dice di quelli che hanno fatto qualche male, e poi procurano rimediarlo".

38 Franciosini, s. v. regañar: "arrabbiare, cioè aver collera tra di se, brontolare, schiacciare, mangiarselo, o scannarselo la collera".

39 Salvatore Battaglia, Grande dizionario della lingua italiana, Unione Tipografico-Editrice Torinese, Torino, 1961, s. v. lindura: "Scrupulosa pulizia, ordine perfetto; aspetto lindo e ordinato" (\$2). 
En muy pocos casos he podido encontrar en el refranero de Italia equivalentes ciertos de los proverbios enumerados por Gracián en el pasaje que analizo. En los casos en los que esto ha sido posible llama la atención que Cattaneo, frente a lo que suelen ser sus hábitos de traductor, haya preferido una versión literal del proverbio español a la sentencia consolidada en su lengua, salvo en un caso: "chi biasma, vuol comprare" 40 $\leftarrow$ "el que dice mal de la mercadería la quiere" 41 . Adviértase en cambio en el resto del pasaje las importantes divergencias: "chi ride inganna" ( $\leftarrow$ "el que ríe regaña") | "tal ti ride in bocca che dietro te l'accocca" (Arthaber, § 1169); "taluno par che burli, e si confessa" ( $\leftarrow$ "el que se burla tal vez se confiesa") | "burlando si dice il vero" (Arthaber, § 192); "chi ti fa piangere ti vuol bene" ( $\leftarrow$ "el que te hace llorar te quiere bien") | "Chi ben ama, ben castiga" (Arthaber, § 245).

\section{El tRAdUCtOR ANTE LOS IDIOMATISMOS}

La actitud ante la frase idiomática es, en lo que respecta al léxico, piedra de toque que a menudo suele proporcionar indicaciones válidas sobre el grado de conocimiento de la lengua de origen por parte del traductor, así como de su habilidad para verter el texto a la lengua receptora, máxime tratándose de un ámbito en el que a pesar de la afinidad de ambos idiomas escasean las coincidencias formales ${ }^{42}$.

Cattaneo demuestra familiaridad con comunes giros fraseológicos del español: "[un cieco che] non vedea nulla" (p. 58) $\leftarrow$ "un ciego que no veía gota" (p. 161); "Meglio fora stirparla [l'erba] dalle radici" (p. 60) $\leftarrow$ "Más valiera arrancarla [la yerba] de cuajo" (p. 164); "Chi è questo, disse, io ho perduto affatto il giudizio" (p. 62) $\leftarrow$ "¡Yo he perdido el tino de todo punto!" (p. 168, cf. ital. perdere il giudizio $\leftarrow$ esp. perder el tino); "non po-

40 Cf. Arthaber, op. cit., $\S 173$.

${ }^{41}$ En esta primera parte de $I C$ ello se producirá tan sólo en una segunda oportunidad: "avverti che non è oro tutto quello che riluce" (p. 54, cf. ARTHABER, $§ 950) \leftarrow$ "Advierte que no lo es [oro] todo lo que reluce" (p. 153).

42 Entre éstas cf. "che [dar buon odore di sè] talvolta costa un occhio della fronte" (p. 75) $\leftarrow$ "cuesta mucho [el que echen buen olor las personas] y tal vez un ojo de la cara" (p. 191) y, de nuevo, en "non ne troverete un capello, sebben voleste pagarlo un occhio" (p. 151) $\leftarrow$ "no se hallará un solo cabello por un ojo de la cara" (p. 317). 
trai tu passare per d'onde passarono tanti saggi, benchè fosse con qualche disgusto?" (p. 64) $\leftarrow$ “¿no podrás tú pasar por donde tantos sabios pasaron, aunque sea tragando saliva?" (p. 171); "Questo nome di cugina a me punto non piace" (p. 138) $\leftarrow$ "Ese nombre de prima no me suena bien" (p. 294) ${ }^{43}$; "far del grande, vantar la genealogia de' gothi" (p. 148) $\leftarrow$ "hacer del don Diego y vengo de los godos" (p. 310); "e chi non la tiene, o principe o bifolco ch'ei sia, partasi dal mondo" (p. 154) $\leftarrow$ "y quien no la tuviere, desde el rey hasta el roque, váyase del mundo" (p. 322).

$\mathrm{Su}$ pericia se extiende hasta interpretar de manera idónea pasajes que entrañaban mayor dificultad: "ordinò che fosse frustato" (p. 61) ६ "lo mandó pasear" (p. 165); "[lo battevano] perchè non avea chi gli facesse spalla; che se l'avesse, faria anch'egli del bravo" (p. 61) ६ "[lo azotan] Porque no tiene espaldas; que, a tenerlas, él hombreara" (p. 165) ${ }^{44}$.

Procediendo en cambio al análisis de pasajes de interpretación dudosa, consideramos en primer lugar el párrafo en el que, ante la perplejidad de Critilo y Andrenio por no dar con hombres eminentes, advierte el centauro Quirón que éstos se hallan prisioneros de sus quimeras y ajenos a las dificultades terrenales ("Crisi VI"), a lo que Critilo responde con unas palabras especialmente intrincadas: "e non sendo Giani di prudenza mostreransi a dito l'un l'altro, e tacciando uno in assenza, partito il mormoratore, si dirà di lui peggio di quel ch'ei disse dell'altro, e succedendo l'uno all'altro, si darà un circolo vizioso infinito" (p. 52) $\leftarrow$ "y, por no ser Janos de prudencia, les picarán las cigüeñas manuales señalándolos con el dedo y diciendo: «¿Éste no es aquel hijo de aquel otro?». De suerte que con lo

${ }^{43}$ La frase es de imposible traducción al italiano dado que Gracián juega con el doble sentido de esp. prima: con referencia a la cuerda prima de un instrumento (y la alusión ha sido arrastrada a su vez por la expresión esp. sonar bien) y como sinónimo de 'mujer licenciosa'. Documentamos dicho juego de palabras en otros textos del siglo xvir; véase Francisco de Quevedo, El Buscón, ed. Domingo Ynduráin, Cátedra, Madrid, 1981, p. 82, n. 8.

44 Para esp. tener espaldas, véase Dicc. Aut., s. v. espalda: tener seguras [DRAE: guardadas] las espaldas: "Es tener seguridad de uno, estar asegurado de él, y tener confianza de que le guardará fe, y le será fiel y amigo"; cf. Franciosini, s. v. espalda: hazer e:: "vale, favorir uno, far spalla a uno" (cf. Grande dizionario della lingua italiana, s. v. spalla: fare s.: "dare un congruo aiuto; sobbarcarsi a un'incombenza gravosa, a un compito arduo e faticoso", que el lexicógrafo define s. v.: "Sostener, aiutare, dar forza e difesa"). Dicc. Aut., s. v. hombrear: "En el sentido moral es quererse igualar con otros en la calidad o prendas" (§3). 
que ellos echaron a las espaldas los demás les darán en el rostro" (p. 151). Para la oscura expresión esp. cigüeña manual, el editor Correa Calderón ${ }^{45}$ remite a Covarrubias, s. v. cigüeña:

Y rematemos este discurso con un término de irrisión, que oy día se usa en Italia, que, para dezir de uno, que detrás dél le van haziendo cocos y burlas, dizen la ciconia; y trae origen que yéndole detrás hazían con la mano y los dedos una forma de pico de cigüeña, como que lo abre y lo cierra, y juntamente haziéndole gestos.

De aceptar tal interpretación, que se ajusta al contexto sin esfuerzo, sorprende que Cattaneo omitiera la alusión al gesto que, como refiere Covarrubias, era de uso corriente en Italia (patria como es sabido de la gestualidad más expresiva), y optara en cambio por simplificar con ital. mostrar(si) a dito $\leftarrow$ esp. señalar con el dedo. Advierto que el traductor opta erróneamente por el verbo pronominal ital. mostrarsi (a dito), como aludiendo a la enemistad que surgirá entre los distintos sabios.

Nótese, asimismo, la inexactitud de verter "tacciando uno in assenza, partito il mormoratore, si dirà di lui peggio di quel ch' ei disse dell'altro" $\leftarrow$ "con lo que ellos echaron a las espaldas los demás les darán en el rostro”, que Cattaneo reelabora como alusión a los chismes con que, a sus espaldas, se criticará al ausente. Con respecto a esp. echar(se) a las espaldas, expresión aún hoy viva en la lengua española, leemos el pasaje de Gracián con la acepción recogida por DRAE, s. v. espalda: echarse uno a las espaldas una cosa: "Olvidar voluntariamente o abandonar un encargo, negocio o preocupación”. Cattaneo, traduciendo con diversa lectura el fragmento, no intenta reproducir el giro en la versión italiana, pese a que su lengua materna le brindaba idéntica expresión (ital. gettarsi qualche cosa dietro le spalle o como registra Franciosini s. v. echar: e. a cuestas $\leftarrow$ ital. mettere o gettare addosso). Omite igualmente la traducción, a renglón seguido, de esp. dar en la cara ${ }^{46}$ que Dicc. Aut. define, s. v. cara: dar en c.: "reprehender y afear públicamente y con aspereza o acrimonia a uno sus malas costumbres y modo de proceder, o algún mal hecho, para que se corrija y emiende" (\$2), la cual es acepción para la que la lengua de nuestro traductor le

45 Ed. cit. supra, n. 21, p. 564, n. ad 1. 3.

${ }^{46}$ Hoy prevalece esp. echar en c., también registrado por DRAE, s. v. cara. 
brindaba por su parte la voz ital. rinfacciare. No doy con una explicación plausible que justifique la adición introducida por Cattaneo: "succedendo l'uno all'altro, si darà un circolo vizioso infinito".

Agrego, en el apartado relativo a errores de traducción, la vistosa tergiversación representada por la equivalencia ital. farsi luogo con una sberettata ('abrirse paso, quitándose reverencialmente el sombrero') $\leftarrow$ esp. entrar de gorra, que sume el pasaje en la ambigüedad: "tanto altri s'ingegnano in questo, che con una sberettata si fanno luogo da entrar per tutto" (p. 129) $\leftarrow$ "guardan otros tanto esta regla, que se entran de gorra en todas partes" (p. 279).

La literalidad es fácil escapatoria para Cattaneo, el cual, en numerosos casos, incurre en expresiones carentes de sentido en italiano. Destaco los siguientes ejemplos: "con occhi più oscuri dell'istessa vita, con più nubi che un maggio" (p. 58) $\leftarrow$ "[un ciego] con unos ojos más oscuros que la misma vileza, con más nubes que un mayo" (p. 161); "Col far le fiche a tutto il mondo e non prendersi travaglio di cosa alcuna" (p. 153) $\leftarrow$ "Echando una higa a todo el mundo y no dándosele nada de cuanto hay" (p. 320) ${ }^{47}$.

\section{RASGOS ANACRÓNICOS DE TRADUCCIÓN}

Cattaneo suele afrontar su tarea con una actitud moderna. Pero no siempre logra mantenerse del todo equidistante y neutral respecto al texto que traduce. La tentación de intervenir en la estructura, forma y contenido de la obra se manifiesta ya desde el prólogo, en sus advertencias al lector italiano. Allí, pese a declarar su intención de mantenerse fiel al texto original castellano, da detalle de las libertades que se ha tomado llegada la hora de traducir la obra de Gracián. A continuación, ejemplifico lo que Cattaneo se ha limitado a exponer en las mencionadas páginas preliminares, siguiendo para ello el mismo orden con el que enumera las licencias del traductor.

47 Franciosini, s. v. higa: "è un modo di disprezzare, serrando il pugno, e mostrando il dito grosso tra quello che chiamano indice, e il dito di mezzo". El lexicógrafo toscano facilita acto seguido la equivalencia ital. far beffe. Agrega para ital. far una fica (o far una castagna): "si dice a quelle persone, e bambini in particolare che ci paion belli, perchè non piglin mal d'occhio"; una forma, pues, de sortilegio que mal acomodo encuentra en la frase que Cattaneo traduce. 
6.1. Universalización de las referencias. Gracián hace frecuente alusión a personajes esclarecidos de su tiempo. Dichos individuos son por regla general españoles y casi siempre contemporáneos a los años en los que el jesuita aragonés escribe $E C$. No son nombres de alcance mundial (y en muchos casos ni siquiera nacional, como observa Cattaneo con malignidad), por lo que el traductor italiano procede a reemplazar sistemáticamente todas estas referencias con alusiones a héroes, caudillos y clásicos de la Antigüedad, los cuales considera patrimonio común de todo aquel que posea una cultura humanística: "in vece di quei Don Primati spagnuoli, appena noti ai nazionali o sudditi della Corona, ch'ei pone per esemplari d'azioni insigni e per idee delle virtù, ho insinuati personaggi eminenti in fama e sapere, e cogniti a tutto il mondo" (p. iv).

Las citas que podría aducir son muy numerosas. Me limito a espigar algunos ejemplos de entre las páginas de esta primera parte de IC: "eccettuandone alcune, che furono (benchè donne) più che virili, come una Semiramide, un'Agrippina, ed altre" (p. 56) $\leftarrow$ "Pero sean excepción de mujeres las que son más que hombres: la gran princesa de Rosano y la excelentísima señora marquesa de Valdueza" (p. 157); "Vissero un Socrate, un Platone, e seguirono il loro viaggio senza tornar indietro" (p. 64) $\leftarrow$ "Vive un entendedor conde de Castrillo y no revienta, un entendido marqués Carreto y pasa" (p. 171).

Me llama la atención la coherencia con la que Cattaneo homogeneiza su relato concentrando su mirada en las crónicas de la Antigüedad. Así procede también aun en los casos en los que los personajes citados por Gracián son de reconocida fama, pero que Cattaneo juzga sin duda como excesivamente cercanos en el tiempo al lector para poder erigirse en modelos excelsos e intemporales: "Pensavi trovar un Aristotile in Stagira, un Agislao in Sparta, un Cesare in Roma, che collo studio e col valore hanno cotanto illustrato l'Universo? Privo è il mondo di tali eroi, appena rimane debole memoria di essi" (pp. 51-52) $\leftarrow$ “Quée? ¿Pensabais hallar ahora un don Alonso el Magnánimo en Italia, un Gran Capitán en España, un Enrico IV en Francia, haciendo corona de su espada y de sus guarniciones lises? Ya no hay tales héroes en el mundo ni aun memoria dellos" (p. 149). Pero la coherencia no es absoluta, lo que permite establecer una jerarquía de personajes modernos: "scusandosi lo scellerato con dire: Doveano venire al tempo di Leone Decimo, o di Francesco Re di Francia, ch'ora non sono quei secoli" (p. 124) $\leftarrow$ "Vivie- 
ran ésos en tiempo de un León X, de un rey Francisco de Francia, que éste no es su siglo" (p. 270).

En otras ocasiones Cattaneo opta por dejar el suceso en la vaguedad, evitando así tener que recurrir a paralelos históricos: "Quanti colpi gli ha fatto errare, uccidendo nel più bel fiore della gioventù quei soggetti, che per le loro virtù meritavano vita immortale, ovvero abbatendoli al suolo d'una mendica povertà... Giva la Fortuna a dar la porpora ad un soggetto eminente in dottrina, ma diegli un colpo sulla mano, donde caduta la raccolse uno, che non n'era punto meritevole" (p. 124) $\leftarrow$ "iQué de golpes la ha hecho errar! Acabó de uno con don Baltasar de Zúñiga, cuando había de comenzar a vivir; acabó con un duque del Infantado, un marqués de Aitona y otros semejantes cuando más eran menester. Dio un revés de pobreza a un don Luis de Góngora, a un Agustín de Barbosa y otros hombres eminentes. Cuando debiera hacerles muchas mercedes, erró el golpe también... Iba a dar la Fortuna un capelo a un Azpilcueta navarro, que hubiera honrado el Sacro Colegio, mas pególa en la mano un tal golpazo, que lo echó en tierra, acudiendo a recogerlo un clerizón” (pp. 270-271).

6.2. Eliminación y corrección de pasajes. Cattaneo se revela crítico poco indulgente. La admiración que siente por la obra magna de Baltasar Gracián no le impide censurar el estilo del autor aragonés cuando juzga que el libro cae en lo prolijo y tedioso, ante lo cual no duda incluso en enmendar el texto original, omitiendo o abreviando pasajes enteros del libro: "anche ho tralasciati alcuni periodi di spagnuolate alquanto tediose, ed avrei fatto lo stesso d'una buona parte del Discorso Quarto della Seconda Parte [El museo del discreto]; ma perch'era già tradotto, l'ho lasciato nel suo essere" (p. iv).

Sospechamos que en algún caso la omisión o reducción del fragmento, escudándose bajo el pretexto de mejorar el estilo del libro, permite al traductor soslayar complejos escollos interpretativos: "altri che faccendoni in tutto s'intromettono, senza sapere svilupparsi dall'intraprese" (p. 30) $\leftarrow$ "Gustarás (que unos se ven, otros se oyen, se tocan y se gustan otros) de los hombres de burlas, que todo lo hacen cuento, sin dar jamás en la cuenta" (p. 117) ${ }^{48}$.

48 Es pasaje que ha planteado dificultades a los editores. Vaíllo acoge la propuesta de Cuesta Dutari, art. cit., p. 151, al igual que hizo Arturo del Hoyo en Obras completas, p. 544. 
6.3. Adiciones del traductor. El intento declarado de Cattaneo por atenuar la prolijidad de la obra castellana, llegando a omitir pasajes enteros, no le impide caer en el defecto opuesto: incorporar al texto de Gracián pensamientos propios o, como ocurre con mayor frecuencia, citas de los clásicos latinos, lo que constituye un alarde de ostentación de su saber humanístico. Algo que resulta evidente en sus palabras preliminares al lector italiano: "Ma perchè sono uomo di coscienza, se ho lasciato alcune cose tediose, n'ho aggiunte altre del mio curiose; mi dichiaro, che quel mio vuol dire ch'io ho letto in altri libri, perchè nihil dictum, quod prius non fuerit dictum. Non è poco per me l'applicarli a tempo e luogo" (p. v).

De entre los muchos ejemplos posibles escojo los siguientes de esta Primera parte, ilustrativos del curioso proceder: "non vi è cosa, che non abbia il suo opposto, col quale combatte, ora vittorioso, ora abattuto, il tutto consiste in quell' agere [et] pati de' filosofi, non trovandosi agente senza il suo correlativo" (p. 22) $\leftarrow$ "no hay cosa que no tenga su contrario con quien pelee, ya con vitoria, ya con rendimiento. Todo es hacer y padecer. Si hay acción, hay repasión" (p. 105); "Quindi è, che tutti i vizi hanno eletto per suo general condottiere il piacere, esso è il solletico degli appetiti, la scorta delle passioni, la vanguardia dei capricci, egli è che attrae prigionieri gli uomini. Trahit sua quemque voluptas [Virgilio, Buc. 2.65]" (p. 106) ${ }^{49} \leftarrow$ "De aquí es que todos los vicios han hecho su caudillo al Deleite: él es el muñidor de los apetitos, precursor de los antojos, adalid de las pasiones y el que trae arrastrados los hombres, tirándole a cada uno su deleite" (p. 240); "Ciascuno ha il tratto e genio particolare; e quindi ebbe origine l'assioma latino: Quot homines, tot sententiae [Terencio, Phormio 454]" (p. 119) ${ }^{50} \leftarrow$ "Cada uno tiene su gusto y su gesto, que no se vive con sólo un parecer” (p. 262).

49 Renzo Tosi, Dizionario delle sentenze latine e greche, Rizzoli, Milano, 1993, § 549: "Ognuno è attratto da ciò che gli piace". La máxima virgiliana es muy del gusto de Cattaneo, quien volverá a insertarla poco después: "Quella dilettevole masnadiera è la famosa Volusia, che noi diciamo diletto, ed i Latini Voluptas, gran fomentatrice dei vizi, che d'essa a gran ragione si dice: Trahit sua quemque Voluptas" (p. 120) $\leftarrow$ "Aquella agradable salteadora es la famosa Volusia, a quien llamamos nosotros delectación, y los latinos voluptas, gran muñidora de los vicios, que a cada uno de los mortales le lleva arrastrado su deleite" (pp. 171-172).

50 Tosi, op. cit., § 537: "Tanti uomini, tanti modi di pensare". 
Con mayor frecuencia la intervención de Cattaneo se limita a identificar el adagio clásico (y vulgarizado por Gracián) para restituirlo a la lengua latina: "ed in ciò vedrai che il fine può chiamarsi anche principio, avverandosi la massima che corruptio unius est generatio alterius; e quando par che il tutto sia giunto al fine, di nuovo risorge" (p. 23) $\leftarrow$ "Con esto verás que el mismo fin es principio. La destrucción de una criatura es generación de la otra. Cuando parece que se acaba todo, entonces comienza de nuevo" (p. 107); "Lesse Critilo la prima iscrizione, che con Orazio [Saturae 1.1.106-7] dicea: Extremum caveas, medium tenuere Beati... Viddero ivi 'l temerario garzone, che mentre ascendeva sopra il carro del Giorno, il genitore gl'incaricava: Medio tutissimus ibis [Ovidio, Metamorfosis 2.137]" (p. 47) $\leftarrow$ "Leyó Critilo el primer letrero, que, con Horacio, decía: «Medio hay en las cosas; tú no vayas por los estremos»... Allí vieron al temerario joven, montando en la carroza de luces, y su padre le decía: «Ve por el medio, y correrás seguro»" (p. 141).

Hay que notar de paso que el latín es la lengua a la que sin discusión Cattaneo vierte casi siempre el adagio, aun cuando la máxima tenga indiscutibles raíces helénicas: "Eternizarono gli antichi ${ }^{52}$ con lettere d'oro nel Tempio di Delfo, e molto più, con caratteri di stima, nella mente de' saggi quel celebre assioma: Nosce te ipsum"53 (p. 92) $\leftarrow$ "Eternizaron con letras de oro los antiguos en las paredes de Delfos, y mucho más con caracteres de estimación en los ánimos de los sabios, aquel célebre sentimiento de Biante: «Conócete a ti mismo»" (p. 221).

\section{Conclusiones}

El Criticón de Baltasar Gracián es obra que, por su peculiar revestimiento formal, por su exacerbada retórica manierista, se erige como un enorme desafío a quienes pretendan verter su texto a otras lenguas. En este trabajo me he aproximado a la

${ }^{51}$ En el fragmento, Cattaneo recurre a la máxima ovidiana literal, así como a su doblete medieval Medium tenuere beati. Véase Tosi, § 1756: "I felici hanno tenuto la via di mezzo".

52 Obsérvese la cautela del traductor italiano que le lleva a descartar la atribución de dicha sentencia a Bías de Priene, tal como afirmaba, en cambio, Gracián.

${ }^{53}$ Es sentencia griega ( $\left.\Gamma \nu \varpi \vartheta \imath ~ \sigma ' \varepsilon \alpha v \tau o ́ v\right)$ de controvertida atribución ora a uno, ora a otro de los siete sabios. Véase Tosi, § 347: "Conosci te stesso". 
traducción italiana llevada a cabo en 1685 por Giovanni Pietro Cattaneo, cuyo nombre parece estar vinculado al ambiente cultural de Padua y, como revela la elección del tipógrafo Pezzana, de la vecina Venecia.

Pese a que de la lectura de esta versión se desprende un considerable bagaje humanístico, no ha sido posible documentar ninguna noticia biográfica relativa a Cattaneo. No he dado tampoco con indicios que apunten a la existencia de obra propia, impresa o manuscrita, y ni siquiera he hallado otras traducciones del español firmadas con su nombre.

Con respecto a la versión italiana, cuya primera parte analizo, reconozco que por lo general Cattaneo se enfrenta a la tarea de traducción de la magna obra de Gracián con una actitud moderna. En el prólogo al lector, Cattaneo enumera las que han sido las directrices fundamentales de su tarea, incluyendo referencias al aparato lexicográfico de que se ha servido. Su fidelidad al texto original es, por lo general, extremada. Antepone el respeto al contenido por encima del intento de conservación del estilo y de las características formales de la obra de Gracián. Se esfuerza, en definitiva, por hacer comprensible al lector italiano una obra que en el prólogo juzga positivamente, sobre todo por el ideario que el autor aragonés ha diseminado en ella.

La prioridad que Cattaneo concede al contenido didáctico de EC no implica un descuido de los aspectos formales. También en este sentido cabe valorar su tarea como extremadamente fiel, manteniendo en la medida de lo posible las particularidades retóricas del texto original y, cuando esto no es posible, buscando soluciones equivalentes en la lengua receptora. Es por este motivo por lo que he examinado pasajes críticos que hubieran tolerado con dificultad una traducción literal y mecánica y que Cattaneo suele afrontar con acierto o, por lo menos, con alternativas que permiten entrever una intensa reflexión.

La actitud de Cattaneo ante la traducción, aunque alejada de presupuestos simplistas, adolece de tachas que con la visión actual cabría juzgar desfavorablemente. En un breve apartado final he recogido aquellas características que revelan aspectos anacrónicos de la versión italiana y algunos rasgos que evidencian una manipulación arbitraria del texto de Gracián.

Aun siendo llamativo que Cattaneo incurra de vez en cuando en estos vicios de traducción poco escrupulosa, lo que más sorprenderá al lector de nuestros días es la actitud contradic- 
toria que en las páginas preliminares lleva a advertir al lector de sus modificaciones al texto castellano, argumentando los motivos por los que ha procedido de esta manera. En cierto modo, abre paso a la conciencia moderna del traductor que, si bien señala la exigencia de respeto al texto ajeno, no consigue librarse del lastre de una actitud que tal vez él consideraba superada.

Jordi Canals Piñas Università degli Studi di Trieste 